\title{
Persepsi Mahasiswa Calon Guru Biologi Tentang Pengembangan Praktikum Biologi Sekolah Menengah: Studi Pengembangan Pembelajaran pada Mahasiswa Pendidikan Biologi FKIP Universitas Muhammadiyah Surakarta
}

\author{
Putri Agustina \\ Progam Studi Pendidikan Biologi, FKIP, Universitas Muhammadiyah Surakarta \\ Kampus I, Jl. Ahmad Yani Tromol Pos I Pabelan Kartasura \\ surat elektronik: pa182@ums.ac.id
}

\begin{abstract}
ABSTRAK
Pengembangan praktikum Biologi sekolah (PPBS) merupakan salah satu matakuliah pilihan yang baru di program studi pendidikan Biologi FKIP Universitas Muhammadiyah Surakarta (UMS). Penelitian ini bertujuan untuk mendeskripsikan persepsi awal mahasiswa calon guru Biologi FKIP UMS tentang Pengembangan Praktikum Biologi Sekolah. Penelitian ini merupakan penelitian deskriptif. Sampel penelitian diambil dari seluruh mahasiswa yang mengikuti matakuliah pilihan PPBS (population sampling) yang terdiri dari dua kelas paralel dengan total mahasiswa sebanyak 35 orang. Data persepsi awal mahasiswa diperoleh dari angket awal perkuliahan PPBS. Berdasarkan hasil analisis angket awal perkuliahan PPBS diketahui bahwa: (I) sebagian besar mahasiswa menyatakan pernah melaksanakan praktikum pada saat duduk di Sekolah Menengah Atas (SMA) meskipun dalam intensitas yang bervariasi; (2) sebagian besar mahasiswa memandang bahwa matakuliah PPBS penting karena akan membekali mahasiswa berbagai keterampilan untuk melaksanakan praktikum; serta (3) sebagian besar mahasiswa berharap bahwa setelah mengikuti matakuliah PPBS mahasiswa dapat memperoleh banyak tambahan materi tentang pengembangan praktikum Biologi sekolah.
\end{abstract}

Kata kunci: Pengembangan Praktikum Biologi Sekolah, KKNI, Calon Guru, persepsi

\section{Pendahuluan}

Program Studi (Prodi) Pendidikan Biologi merupakan salah satu dari II program studi yang dimiliki oleh Fakultas Keguruan dan Ilmu Pendidikan (FKIP) Universitas Muhammadiyah Surakarta (UMS). Prodi Pendidikan Biologi FKIP UMS memiliki empat profil lulusan yang salah satunya adalah sebagai pengelola laboratorium dan pengembang bahan ajar praktikum. Capaian pembelajaran program studi (program learning outcomes/PLO) yang berkaitan dengan profil lulusan tersebut adalah "mampu merencanakan, melaksanakan, mengevaluasi, dan merefleksikan praktikum Biologi melalui berbagai pendekatan berbasis laboratorium sehingga mampu mendukung terselenggaranya pembelajaran Biologi di sekolah dan masyarakat" serta "mampu mengelola dan mengorganisasi sumberdaya laboratorium Biologi secara bertanggung jawab kepada pemangku kepentingan” (Tim Penyusun Kurikulum Prodi P. Biologi FKIP UMS, 2015). Upaya untuk mencapai PLO dilakukan melalui berbagai matakuliah yang ada pada prodi Pendidikan Biologi FKIP UMS.

Salah satu matakuliah untuk mencapai PLO seperti tersebut di atas adalah Pengembagan Praktikum Biologi Sekolah (PPBS). PPBS merupakan salah satu Mata Kuliah Pilihan (MKP) baru di Prodi Pendidikan Biologi FKIP UMS. PPBS merupakan MKP yang secara umum memberikan bekal pada calon guru untuk dapat mengembangkan pembelajaran Biologi berbasis praktikum secara menyeluruh meliputi analisis kurikulum, kedalaman materi, pengembangan bahan ajar praktikum, pengembangan lembar kerja siswa, dan secara langsung melakukan uji coba terhadap satuan acara praktikum (bahan ajar dan lembar kerja siswa) yang telah dikembangkan dalam pembelajaran riil di kelas (Kurikulum Prodi P. Biologi FKIP UMS, 2015). Matakuliah PPBS sangat sesuai dengan profil Prodi Pendidikan Biologi FKIP UMS yang menghasilkan lulusan sebagai guru Biologi dan pengelola laboratorium khususnya laboratorium Biologi. 
Praktikum merupakan salah satu metode pembelajaran yang tidak dapat dipisahkan dari pembelajaran sains termasuk Biologi. Secara harfiah, praktikum berasal dari kata praktik yang artinya pelaksanaan secara nyata apa yang disebut dalam teori. Praktikum menurut Agustina (2015)mmerupakan bagian dari pengajaran yang bertujuan agar siswa memperoleh kesempatan untuk menguji dan melaksanakan di keadaan nyata, apa yang diperoleh dari teori dan penjelasan praktik. Pengertian praktikum yang lain dikemukakan oleh Suryosubroto (2002) yang menyatakan bahwa praktikum adalah metode dimana dalam proses belajar mengajar guru menekankan pada siswa untuk menemukan sendiri informasi yang bertujuan mengajarkan keterampilan menyelidiki dan memecahkan masalah sebagai alat bagi siswa untuk mencapai tujuannya.

Praktikum menurut Hayat, dkk. (20II) dipandang sebagai salah satu strategi pembelajaran yang baik dan sejalan dengan hakikat pembelajaran berbasis konstruktivisme. Pembelajaran berbasis praktikum mengarahkan siswa pada experiental learning (belajar berdasarkan pengalaman konkrit), diskusi dengan sesama teman, yang selanjutnya akan memperoleh ide dan konsep yang baru. Oleh karena itu, belajar berbasis praktikum dipandang sebagai proses penyusunan pengetahuan dari pengalaman konkrit, aktivitas kolaboratif, dan refleksi serta interpretasi. Karena beberapa alasan tersebut, praktikum juga disebut sebagai bentuk lain pengajaran klasikal yang menjadi bagian integral pada pembelajaran di beberapa bidang (sains, teknologi, olah raga, dan sebagainya).

Praktikum merupakan bagian yang tidak dapat dipisahkan dari pembelajaran IPA, termasuk Biologi. Hal ini didukung pendapat Rustaman (2006) bahwa praktikum merupakan bagian integral dari pembelajaran sains (IPA). Hal ini menurut Sumardjo (2013) yang menyebabkan IPA sering disebut juga dengan experimental science. Proses belajar mengajar dengan praktikum memberi kesempatan pada siswa untuk mengalami sendiri, mengikuti suatu proses, mengamati suatu objek, menganalisis, membuktikan, dan menarik kesimpulan sendiri tentang suatu objek, keadaan atau proses tertentu. Pada kegiatan praktikum, terjadi penerapan beragam keterampilan proses sains sekaligus pengembangan sikap ilmiah yang mendukung proses perolehan pengetahuan (produk keilmuan) dalam diri siswa. Hal ini tampak bahwa praktikum memiliki kedudukan yang sangat penting dalam pembelajaran IPA, karena melalui praktikum siswa memiliki peluang untuk mengembangkan dan menerapkan keterampilan proses sains dan sikap ilmiah sebagai wujud dari penguasaan pengetahuan yang dimilikinya.

Penelitian ini bertujuan untuk mendeskripsikan persepsi awal mahasiswa calon guru Biologi FKIP UMS tentang Pengembangan Praktikum Biologi Sekolah.
Persepsi awal mahasiswa penting untuk menentukan tindakan apa yang dapat dikembangkan dalam rangka memberikan bekal mahasiswa calon guru agar dapat melaksanakan pembelajaran Biologi berbasis praktikum.

\section{Metode Penelitian}

Penelitian ini dilaksanakan di Prodi Pendidikan Biologi FKIP Universitas Muhammadiyah Surakarta pada bulan September 20I5. Penelitian ini merupakan penelitian deskriptif. Penelitian deskriptif menurut Sugiyono (2006) merupakan penelitian yang dilakukan untuk mengetahui nilai variabel mandiri, baik satu variabel atau lebih (independen) tanpa membandingkan atau menghubungkan dengan variabel lainnya.

Sampel penelitian diambil dari seluruh mahasiswa yang mengikuti matakuliah pilihan PPBS atau disebut population sampling yang terdiri dari dua kelas paralel dengan total mahasiswa sebanyak 35 orang. Data persepsi awal mahasiswa diperoleh dari angket awal perkuliahan PPBS. Data yang diperoleh dari angket awal perkuliahan dianalisis dengan metode deskriptif. Data ditabulasi dengan menyusun ke dalam tabel sistematis kemudian dihitung persentasenya untuk selanjutnya dianalisis dan diinterpretasikan. Analisis data dihitung menggunakan rumus berikut.

$$
\mathrm{P}=\mathrm{F} / \mathrm{n}
$$

Keterangan:

$$
\begin{array}{ll}
\mathrm{P} & =\text { Persentase } \\
\mathrm{F} & =\text { Jumlah jawaban yang diperoleh } \\
\mathrm{n} & =\text { Jumlah responden }
\end{array}
$$

Untuk menafsirkan besarnya persentase yang diperoleh dari tabulasi data, digunakan metode menurut Supardi (1979) yaitu:

$\begin{array}{ll}\text { I-25\% } & \text { sebagian kecil } \\ 26-49 \% & \text { hampir setengah } \\ 50 \% & \text { setengah } \\ 51-75 \% & \text { sebagian besar } \\ 76-99 \% & \text { pada umumnya } \\ 100 \% & \text { seluruhnya }\end{array}$

Metode penelitian pada dasarnya merupakan langkah-langkah atau prosedur yang akan dilakukan dalam pengumpulan, pengolahan dan analisis data untuk mendeskripsi pemecahan masalah penelitian dan menguji hipotesis.

\section{Hasil dan Pembahasan}

Persepsi awal mahasiswa tentang PPBS diperoleh dari angket awal perkuliahan PPBS. Angket awal diberikan pada pertemuan pertama matakuliah PPBS tahun ajaran 2015/2016 semester gasal. Angket awal perkuliahan terdiri dari beberapa poin pertanyaan yang akan dijelaskan sebagai berikut. Ringkasan hasil rekap angket awal perkuliahan PPBS ditunjukkan pada Tabel I. 
Tabel I. Hasil Angket Awal Persepsi Mahasiswa tentang PPBS

\begin{tabular}{|c|c|c|c|c|}
\hline No & Pertanyaan & Jawaban yang muncul & Frekuensi & $\%$ \\
\hline \multirow[t]{3}{*}{$\mathrm{I}$} & Apakah Anda pernah & a. Jarang & $\mathrm{I} 4$ & 40 \\
\hline & melaksanakan praktikum & b. Belum & I4 & 40 \\
\hline & Biologi? & c. Sering & 7 & 20 \\
\hline \multirow[t]{3}{*}{2} & $\begin{array}{l}\text { Bagaimana pengalaman Anda } \\
\text { mengembangkan pembelajaran } \\
\text { Biologi dengan berbasis }\end{array}$ & $\begin{array}{l}\text { a. Belum pernah, karena belum } \\
\text { melaksanakan PPL dan atau } \\
\text { Magang } 3\end{array}$ & I4 & 40 \\
\hline & praktikum? & b. Pernah, pada saat PPL & 20 & 57 \\
\hline & & $\begin{array}{l}\text { c. Pernah, karena memang sudah } \\
\text { mengajar di sekolah menengah }\end{array}$ & $\mathrm{I}$ & 3 \\
\hline \multirow[t]{9}{*}{3} & $\begin{array}{l}\text { Apa pendapat Anda tentang } \\
\text { matakuliah PPBS? }\end{array}$ & $\begin{array}{l}\text { a. Baik, karena dapat menjadi modal } \\
\text { untuk melaksanakan praktikum } \\
\text { kelak ketika menjadi guru }\end{array}$ & $2 \mathrm{I}$ & 60 \\
\hline & & $\begin{array}{l}\text { b. Dapat mengajarkan bagaimana } \\
\text { membuat alat peraga praktikum }\end{array}$ & I & 3 \\
\hline & & $\begin{array}{l}\text { c. Dapat memberi bekal tentang } \\
\text { manajemen laboratorium }\end{array}$ & 2 & 5.7 \\
\hline & & $\begin{array}{l}\text { d. Memperoleh keterampilan dan } \\
\text { kemandirian dalam melaksanakan } \\
\text { praktikum }\end{array}$ & 2 & 5.7 \\
\hline & & $\begin{array}{l}\text { e. Memperoleh pengetahuan tentang } \\
\text { alat dan bahan praktikum }\end{array}$ & $\mathrm{I}$ & 3 \\
\hline & & $\begin{array}{l}\text { f. Memperoleh bekal lain selain } \\
\text { kewirausahaan }\end{array}$ & I & 3 \\
\hline & & $\begin{array}{l}\text { g. Mendalami praktikum Biologi di } \\
\text { sekolah }\end{array}$ & $\mathrm{I}$ & 3 \\
\hline & & h. Sebagai sarana pendalaman materi & 5 & I 4.3 \\
\hline & & i. Belum tahu & 2 & 5.7 \\
\hline \multirow[t]{6}{*}{4} & $\begin{array}{l}\text { Apa harapan Anda setelah } \\
\text { mengikuti matakuliah PPBS? }\end{array}$ & $\begin{array}{l}\text { a. Memperoleh tambahan materi } \\
\text { tentang pengembangan praktikum } \\
\text { Biologi sekolah }\end{array}$ & 22 & 62.8 \\
\hline & & $\begin{array}{l}\text { b. Memperoleh pengetahuan tentang } \\
\text { strategi agar praktikum berjalan } \\
\text { dengan baik }\end{array}$ & $\mathrm{I}$ & 3 \\
\hline & & $\begin{array}{l}\text { c. Memperoleh pengetahuan } \\
\text { bagaimana melaksanakan } \\
\text { praktikum dengan kreatif, } \\
\text { inovatif, dan menyenangkan }\end{array}$ & 6 & 17.2 \\
\hline & & $\begin{array}{l}\text { d. Memperoleh pengalaman } \\
\text { melaksanakan praktikum }\end{array}$ & 2 & 5.7 \\
\hline & & $\begin{array}{l}\text { e. Memperoleh pengalaman } \\
\text { menyusun lembar kerja siswa dan } \\
\text { petunjuk praktikum }\end{array}$ & 3 & 8.5 \\
\hline & & f. Belum tahu & $\mathrm{I}$ & 3 \\
\hline
\end{tabular}

Pertanyaan pertama yaitu "Apakah Anda pernah melaksanakan praktikum Biologi dan pada materi apa?”. Berdasarkan hasil angket pada Tabel I, maka diketahui bahwa hampir setengah (40\%) mahasiswa menyatakan belum pernah melaksanakan praktikum pada saat duduk di sekolah menengah, 40\% mahasiswa menyatakan bahwa pernah melaksanakan praktikum meskipun dalam intensitas yang jarang, sedangkan sebagian kecil (20\%) menyatakan sering melaksanakan praktikum pada saat duduk di sekolah menengah. Beberapa materi yang pernah dipraktikumkan berdasarkan jawaban mahasiswa antara lain: pengamatan jaringan tumbuhan, pembelahan sel, respirasi (pernafasan), percobaan Ingenhous, Sach, biokimia, perkecambahan tumbuhan, difusi, dan osmosis.

Pertanyaan kedua yaitu "Bagaimana pengalaman Anda dalam mengembangkan praktikum Biologi sekolah?”. Sebagian besar mahasiswa menyatakan pernah memiliki pengalaman mengembangkan praktikum Biologi sekolah yaitu pada saat kegiatan Program Pengalaman Lapangan (PPL). Sedangkan hampir setengah (40\%) menyatakan belum pernah karena belum menempuh PPL. 
Pertanyaan ketiga yaitu "Apa pendapat Anda tentang matakuliah PPBS?”. Sebagian besar mahasiswa menyatakan bahwa matakuliah ini merupakan matakuliah yang memberikan bekal keterampilan dan pengetahuan sebagai modal untuk melaksanakan praktikum.

Pertanyaan keempat yaitu "Apa harapan Anda setelah mengikuti matakuliah PPBS?”. Sebagian besar mahasiswa menyatakan bahwa setelah mengikuti matakuliah ini diharapkan akan dapat mendapatkan tambahan materi tentang pengembangan praktikum Biologi sekolah.

Hasil angket awal perkuliahan PPBS menunjukkan bahwa mahasiswa secara umum telah memiliki persepsi awal yang baik tentang matakuliah PPBS. Pengetahuan tentang pembelajaran Biologi berbasis praktikum penting dimiliki mahasiswa calon guru karena merupakan salah satu komponen dari kompetensi pedagogi.

Kemampuan melaksanakan praktikum sebagai salah satu metode pembelajaran Biologi merupakan wujud dari penguasaan Pedagogical Knowledge (PK) dan Content Knowledge (CK). PK dalam Permendiknas Nomor 16 Tahun 2007 tentang Standar Kualifikasi Akademik dan Kompetensi Guru disebut sebagai kompetensi pedagogis yaitu kemampuan guru dalam mengelola pembelajaran yang terdiri dari pemahaman terhadap siswa, perencanaan, implementasi pembelajaran dan evaluasi hasil belajar. Sedangkan CK dalam Permendiknas Nomor I6 Tahun 2007 tentang Standar Kualifikasi Akademik dan Kompetensi Guru disebut sebagai kompetensi profesional yaitu penguasaan materi pembelajaran secara luas dan mendalam yang mencakup penguasaan materi kurikulum mata pelajaran di sekolah dan substansi keilmuan yang menaungi materinya serta penguasaan terhadap struktur dan metodologi keilmuannya.

\section{Simpulan}

Berdasarkan hasil analisis angket awal perkuliahan PPBS diketahui bahwa: (I) sebagian besar mahasiswa menyatakan pernah melaksanakan praktikum pada saat duduk di Sekolah Menengah Atas (SMA) meskipun dalam intensitas yang bervariasi; (2) sebagian besar mahasiswa memandang bahwa matakuliah PPBS penting karena akan membekali mahasiswa berbagai keterampilan untuk melaksanakan praktikum; serta (3) sebagian besar mahasiswa berharap bahwa setelah mengikuti matakuliah PPBS mahasiswa dapat memperoleh banyak tambahan materi tentang pengembangan praktikum Biologi sekolah.

\section{Daftar Pustaka}

Agustina, P. 2015. Modul Praktek Pengembangan Praktikum Biologi Sekolah. Surakarta: Laboratorium Biologi FKIP Universitas Muhammadiyah Surakarta.

Hadi, S. I98I. Metode Research. Yogyakarta: Yayasan Penelitian Fakultas Psikologi UGM.
Hayat, M.S., S., Anggraini, dan S., Redjeki. $201 \mathrm{I}$. Pembelajaran Berbasis Praktikum pada Konsep Invertebrata untuk Pengembangan Sikap Ilmiah Siswa. Bioma 2(2): I4I-I52.

Kementerian Pendidikan Nasional. 2007. Peraturan Menteri Pendidikan Nasional (Permendiknas) Nomor I6 Tahun 2007 tentang Standar Kualifikasi Akademik dan Kompetensi Guru.

Rustaman, N. 2006. Strategi Pembelajaran Biologi. Bandung: Jurusan Biologi FPMIPA Universitas Pendidikan Indonesia.

Sugiyono. 2006. Metode Penelitian Administrasi. Edisi Revisi. Bandung: Alfabeta.

Sumardjo, A.P. 2013. Pengaruh Penggunaan Metode Praktikum dengan Model Pembelajaran Kooperatif Tipe Numbered Head Together (NHT) terhadap Keterampilan Proses Sains Siswa pada Materi Pokok Ciri-Ciri Makhluk Hidup (Kuasi Eksperimen pada Siswa Kelas VII SMP Negeri 3 Metro Semester Genap Tahun Pelajaran 2012/2013). Lampung: Fakultas Keguruan dan Ilmu Pendidikan Universitas Lampung.

Supardi, A. 1979. Statistik. Bandung: Fakultas Tarbiyah IAIN Sunan Gunung Jati.

Suryosubroto, B. 2002. Proses Belajar Mengajar di Sekolah. Jakarta: Rineka Cipta.

Tim Penyusun Kurikulum Prodi P. Biologi FKIP UMS. 2015. Dokumen Kurikulum Sarjana Berbasis KKNI Prodi Pendidikan Biologi FKIP UMS. Surakarta: Universitas Muhammadiyah Surakarta. 